\title{
Vitamin D Deficiency as an Ignored Cause of Hypocalcemia in Acute Illness: Report of 2 Cases and Review of Literature
}

\author{
Hiroshi Noto $^{*}, 1,2$ and Howard J. Heller ${ }^{1}$ \\ ${ }^{I}$ Division of Endocrinology and Metabolism, Department of Internal Medicine, The University of Texas Southwestern \\ Medical Center, 5323 Harry Hines Blvd, Dallas TX 75390, USA \\ ${ }^{2}$ Division of Endocrinology and Metabolism, Department of Medicine, Toshiba Hospital, 6-3-22 Higashi Oi, Shinagawa, \\ Tokyo, 140-8522, Japan
}

\begin{abstract}
We describe the clinical and laboratory findings in 2 cases of hypocalcemia secondary to vitamin D deficiency in intensive care unit and the response of calcium to treatment. We also discuss the mechanism and review pertinent literature. The first patient was admitted due to stroke. Laboratory data included serum calcium $7.6 \mathrm{mg} / \mathrm{dl}$, intact parathyroid hormone (PTH) $891.6 \mathrm{pg} / \mathrm{ml}, 25$-hydroxyvitamin D (25-OH-D) $7 \mathrm{ng} / \mathrm{ml}$ (17.5 nmol/1), 1,25-dihydroxyvitamin D (1,25$\mathrm{OH}-\mathrm{D}) 43 \mathrm{pg} / \mathrm{ml}(103.2 \mathrm{nmol} / \mathrm{l})$, and corrected QT (QTc) interval $494 \mathrm{msec}$. After two weeks of treatment with oral calcium and ergocalciferol, serum calcium and intact PTH levels and QTc interval normalized. The second patient was transferred for the management of disseminated cytomegalovirus infection. Laboratory work-up revealed serum calcium 7.7 $\mathrm{mg} / \mathrm{dl}$, creatinine $4.3 \mathrm{mg} / \mathrm{dl}$, intact PTH $207.5 \mathrm{pg} / \mathrm{ml}, 25-\mathrm{OH}-\mathrm{D}<5 \mathrm{ng} / \mathrm{ml}(<12.5 \mathrm{nmol} / \mathrm{l}), 1,25-\mathrm{OH}-\mathrm{D}<10 \mathrm{pg} / \mathrm{ml}(<24$ $\mathrm{nmol} / \mathrm{l}$ ), and QTc interval $505 \mathrm{msec}$. After treatment for vitamin D deficiency and infection, we observed normalization of creatinine, corrected calcium, intact PTH and QTc interval. The clinical courses were uneventful in both cases. In conclusion, we would like to emphasize that vitamin D status should be evaluated in patients with hypocalcemia in acute settings because vitamin D deficiency is common and readily treatable, and there may be clear life-threatening consequences if it is not treated.
\end{abstract}

Keywords: Vitamin D, hypocalcemia, hyperparathyroidism, acute illness.

\section{INTRODUCTION}

Vitamin D deficiency is common in inpatients [1], outpatients [2], the elderly [3,4], diabetic patients [5] and even in healthy adults [6-8]. It causes long-term sequelae including secondary hyperparathyroidism, bone loss, mineralization defects and fracture. Simple treatment with vitamin D and calcium has been shown to correct serum calcium and to reduce the fracture risk [9-12]. In addition, resulting hypocalcemia may lead to serious acute sequelae including neuromuscular irritability, tetany, laryngospasm [13], seizure, arrhythmia, heart failure [14], and death. Despite its high prevalence and important public health implications, vitamin D deficiency is frequently overlooked.

Hypocalcemia and consequent hyperparathyroidism are common in acute illness such as sepsis, acute pancreatitis, or major surgery, and they have been reported to predict mortality in these settings [15-22]. Although vitamin D deficiency is frequent and it has been described as a cause of hypocalcemia, it has received little attention and only few reports scrutinized vitamin D status and response in acute disease [23-26].

We describe 2 cases of severe vitamin D deficiency with persistent hypocalcemia and marked hyperparathyroidism during critical illness. After vitamin D treatment, we -

*Address correspondence to this author at the Division of Endocrinology and Metabolism, Department of Medicine, Toshiba Hospital, 6-3-22 Higashi Oi, Shinagawa, Tokyo, 140-8522, Japan; Tel: +81-3-3764-0511; Fax: +813-3764-3415; E-mail: noto-tky@umin.ac.jp observed normalization of serum calcium, intact parathyroid hormone (PTH), and corrected QT (QTc) interval on electro cardiogram (ECG) in both cases. We would like to emphasize that presence of risk factors for vitamin D deficiency should raise alert about the need to test vitamin D status in patients with hypocalcemia in acute settings because vitamin $\mathrm{D}$ deficiency is common and readily treatable, and there may be clear morbid consequences if it is not treated.

\section{CASE REPORTS}

\section{Case 1}

A 67-year-old man with no past medical history was found in coma and admitted to the intensive care unit in winter. Soon after arrival, he developed cardiopulmonary failure and was intubated. Physical examination showed fixed constricted pupils, irregular heart beat, and slightly spastic lower extremities. Laboratory data included calcium $7.6 \mathrm{mg} / \mathrm{dl}$ (normal, 8.4-10.2 mg/dl), phosphorus $1.9 \mathrm{mg} / \mathrm{dl}$ (normal, 2.4-4.5 mg/dl), magnesium $1.7 \mathrm{mEq} / 1$ (normal, 1.4-1.8 $\mathrm{mEq} / \mathrm{l}$ ), albumin $4.0 \mathrm{~g} / \mathrm{dl}$ (normal, 3.5-5.2 $\mathrm{g} / \mathrm{dl}$ ), thyroid stimulating hormone (TSH) $55 \mu \mathrm{IU} / \mathrm{ml}$ (normal, 0.4-4.5 $\mu \mathrm{IU} / \mathrm{ml}$ ), free thyroxine $\left(\mathrm{FT}_{4}\right) \quad 0.5 \mathrm{ng} / \mathrm{dl}$ (normal, 0.76-1.79 $\mathrm{ng} / \mathrm{dl}$ ), and normal liver/renal functions. ECG showed atrial fibrillation and QTc interval $494 \mathrm{msec}$ (normal, less than or equal to $440 \mathrm{msec}$ ). Initial head CT scan was negative.

He was diagnosed with stroke, atrial fibrillation, hypothyroidism, and hypocalcemia. Subsequently, he was given levothyroxine $50 \mu \mathrm{g}$ daily and one dose of intravenous calcium gluconate $1000 \mathrm{mg}$ (elementary calcium $90 \mathrm{mg}$ ) was 
given over 10 minutes. Brain MRI and repeat head CT 2-3 days after admission revealed marked brain stem infarction. He regained consciousness on hospital day 7 and he was extubated on day 10. Serum albumin stayed in the normal range throughout the course of hospitalization. Further workup for hypocalcemia revealed serum hydroxyvitamin D (25OH-D) $7 \mathrm{ng} / \mathrm{ml}$ (17.5 nmol/1; normal, 8-38 ng/ml [20-95 nmol/1]), 1,25-dihydroxyvitamin D (1,25-OH-D) $43 \mathrm{pg} / \mathrm{ml}$ (103.2 nmol/1; normal, 22-67 pg/ml [52.8-160.8 nmol/1]) both measured by radioimmunoassay, and intact PTH 892 $\mathrm{pg} / \mathrm{ml}$ (normal, 14-72 pg/ml) measured by electrochemiluminescent immunoassay. Ionized calcium was not measured and an ultrasound evaluation of thyroid/parathyroid was not performed. On day 9, he was started on ergocalciferol 50,000 units daily for 2 weeks in conjunction with oral calcium (500 mg elemental) with vitamin D three times daily. Subsequently, serum calcium level rose to near-normal level (Fig. 1) and intact PTH level declined to $378 \mathrm{pg} / \mathrm{ml}$ on day 10,291 $\mathrm{pg} / \mathrm{ml}$ on day 12 , and $44 \mathrm{pg} / \mathrm{ml}$ on day 28 . QTe interval shortened to $400 \mathrm{msec}$.

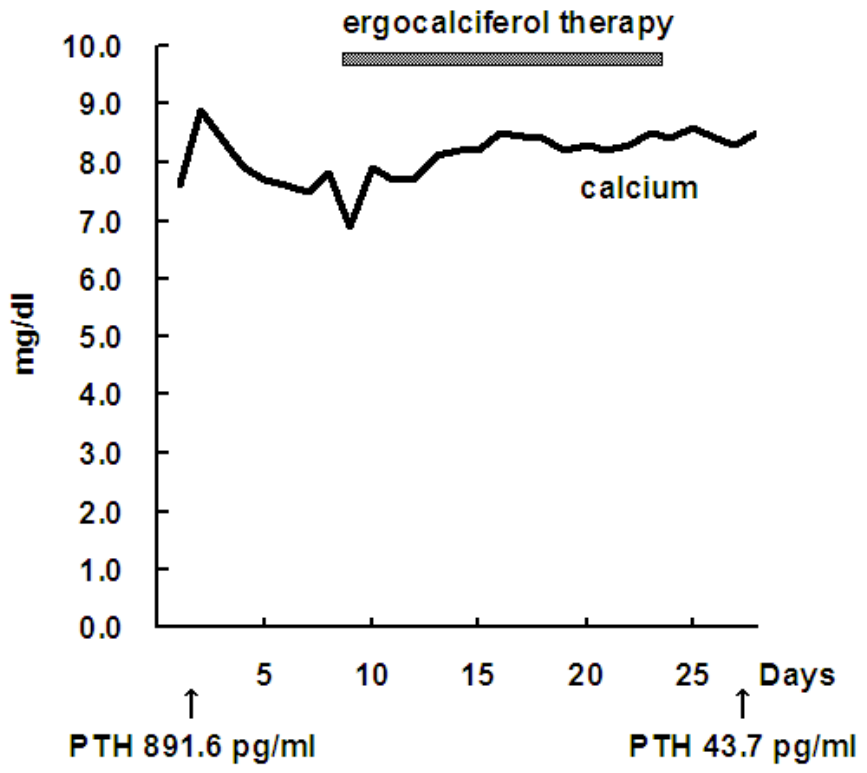

Fig. (1). Change in serum calcium concentration with time in Case 1. $\mathrm{PTH}=$ parathyroid hormone.

\section{Case 2}

A 50-year-old man was admitted to another hospital in winter because of acute onset respiratory failure for which he was intubated. He was found to have disseminated cytomegalovirus infection with acute renal failure, and he was transferred to our institution for intensive management one week later. His past medical history was significant for myasthenia gravis and hypothyroidism. The serum calcium level and the renal function one week prior to this event were normal. His medications on transfer included intravenous immunoglobulin, mycophenolate mofetil, levothyroxine, and intravenous ganciclovir. Laboratory data on transfer were as follows: creatinine $4.3 \mathrm{mg} / \mathrm{dl}$, calcium 7.7 (albumin-adjusted 8.4) $\mathrm{mg} / \mathrm{dl}$, phosphorus $2.4 \mathrm{mg} / \mathrm{dl}$, magnesium $1.8 \mathrm{mEq} / \mathrm{l}$, albumin $3.1 \mathrm{~g} / \mathrm{dl}$, TSH $0.4 \mathrm{mIU} / \mathrm{l}$, and $\mathrm{FT}_{4} 0.6 \mathrm{ng} / \mathrm{dl}$. The other liver function test was normal. QTc interval on ECG was 505 msec.
Subsequently, he developed septic shock due to disseminated cytomegalovirus infection. Additional endocrinological work-up for persistent hypocalcemia showed ionized calcium $4.6 \mathrm{mg} / \mathrm{dl}$ (normal, 4.6-5.4 mg/dl), 25-OH-D $<5 \mathrm{ng} / \mathrm{ml} \quad(<12.5 \mathrm{nmol} / \mathrm{l}), 1,25-\mathrm{OH}-\mathrm{D} \quad<10 \mathrm{pg} / \mathrm{ml} \quad(<24$ $\mathrm{nmol} / \mathrm{l})$, and intact PTH $207.5 \mathrm{pg} / \mathrm{ml}$. On day 11 , he was initiated on ergocalciferol 50,000 units daily for 2 weeks and oral calcium (500 mg elemental) with vitamin D three times daily. Serum creatinine level returned to normal on day 14 . He regained consciousness on day 16 and he was extubated on day 19. Serum albumin remained in the range of 2.1-2.4 $\mathrm{g} / \mathrm{dl}$ during the rest of hospitalization. Corrected calcium level returned to normal range (Fig. 2) and intact PTH level decreased to $49.7 \mathrm{pg} / \mathrm{ml}$ on day 28 . QTc interval shortened to $430 \mathrm{msec}$.

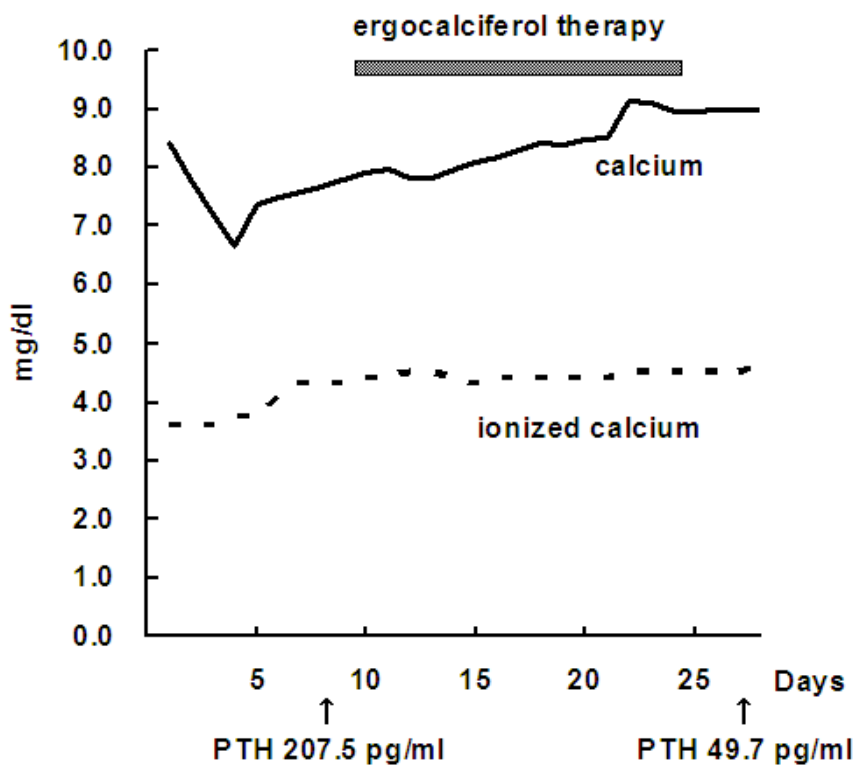

Fig. (2). Change in serum calcium concentration with time in Case 2. $\mathrm{PTH}=$ parathyroid hormone.

\section{DISCUSSION}

These two patients with critical illness had hypocalcemia and marked hyperparathyroidism secondary to vitamin D deficiency. Their responses to treatment with vitamin D support vitamin D deficiency as the most plausible cause of hypocalcemia. Moreover, the low serum phosphate levels in both cases were consistent with vitamin D deficiencyinduced hyperparathyroidism since PTH induces phosphaturia and hypophosphatemia.

Hypocalcemia is frequent in the critically ill [15]. It can lead to serious conditions $[13,14]$; it has been suggested that hypocalcemia is associated with the severity of disease and fairly predicts mortality in critically ill patients [15-17, 19]. Hypocalcemia in critical illness is presumably multifactorial. In addition to the common causes of hypocalcemia (Table 1), other factors have been postulated $[15,16,19,21,23,26$, 27]: failure of the kidney to produce $1,25-\mathrm{OH}-\mathrm{D}$, failure of the liver to produce 25-OH-D, effects of cytokine, blunted response of the bone to $\mathrm{PTH}$, relative hypoparathyroidism, and chelation by citrate in transfused blood. However, we speculate that vitamin D deficiency may be an important cause in light of its high prevalence and poor nutritional state 
with lack of sunlight exposure in very sick patients [28] like our pateints, although very few studies have published low to low-normal vitamin D level in patients with acute diseases (Table 2) [23-26].

\section{Table 1. Causes of Hypocalcemia}

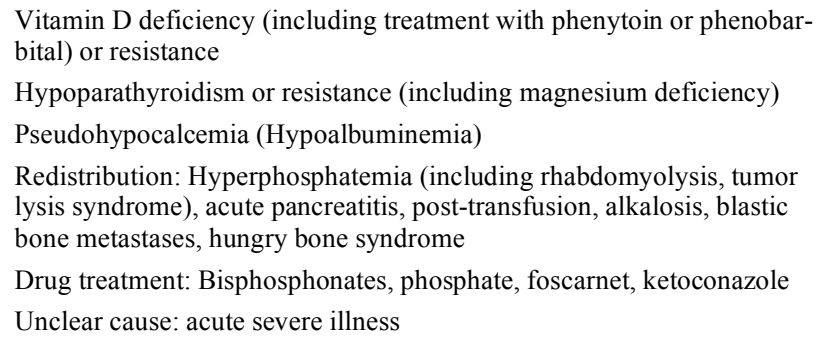

The major risk factors of vitamin D deficiency are listed in Table 3. Most mineral experts suggest that the lower limit of normal range should be $>20 \mathrm{ng} / \mathrm{ml}(50 \mathrm{nmo} / \mathrm{l})$ [36] or even $30 \mathrm{ng} / \mathrm{ml}(75 \mathrm{nmol} / \mathrm{l})$ [37, 38]. In Case 1, vitamin D deficiency was presumably attributable to little sunlight exposure and poor intake of vitamin D. In Case 2, longstanding poor dietary intake of vitamin D before transfer in addition to poor sunlight exposure probably accounted for the undetectable 25-OH-D level. Malnutrition is also suggested by hypoalbuminemia. In addition, it is also likely that 1,25-OH-D depletion resulted from superimposing acute renal failure and that sepsis and acute renal failure exacerbated hypocalcemia and secondary hyperparathyroidism. In both cases, liver function was intact and vitamin D resistance was unlikely because $1,25-\mathrm{OH}-\mathrm{D}$ was not high.

Table 2. Vitamin D Levels in Reported Cases with Acute Illness

\begin{tabular}{|c|c|c|c|c|}
\hline & Diagnosis & Cases (n) & 25-OH-D (ng/ml) & 1,25-OH-D (pg/ml) \\
\hline \hline \multirow{2}{*}{ Lind, et al. $2000[23]$} & sepsis & 13 & $12.0(5.6)$ & $17.5(8.8)$ \\
\cline { 2 - 5 } & surgery & 13 & $13.6(4.0)$ & $17.9(7.5)$ \\
\hline \multirow{3}{*}{ Muller, et al. $2000[24]$} & infection & 48 & $8.8(7.7)$ & $32.4(15.0)$ \\
\cline { 2 - 5 } & no infection & 20 & $8.1(6.1)$ & $25.0(13.1)$ \\
\cline { 2 - 5 } & sepsis & 33 & $6.3(5.2)$ & $27.7(23.5)$ \\
\hline Zaloga, et al. $1987[25]$ & sepsis & 12 & $15.1(8.0)$ & $20.5(23.6)$ \\
\hline Desai, et al. $1987[26]$ & normocalcemia & 10 & $26.5(17.0)$ & not measured \\
\cline { 2 - 5 } & hypocalcemia & 28 & $15.3(9.2)$ & not measured \\
\hline
\end{tabular}

PTH is one of the major regulators of extracellular calcium lying in a negative feedback way responding to changes in ionized calcium levels and vitamin D. PTH reportedly affects vascular smooth cells and ventricular myocytes [29], and impairs cardiac energy production, transfer, and utilization by enhanced entry and the accumulation of calcium in the myocardium [30] leading to development of cardiovascular disease [20,31-33]. There have been several reports of elevated PTH value in patients with acute disease, which was associated with disease severity and poor outcome [17-20]. In most cases with acute illness, hypocalcemia was not restored by elevated concentration of PTH. This points to the possibility that secretion or action of PTH is relatively impaired in addition to vitamin D deficiency [15, $25,34]$. It is also conceivable that PTH might affect cytokine link $[19,27]$ and immune system [35], resulting in refractory hypocalcemia.

In Case 1, hypocalcemia had not been restored by high PTH and the initial PTH value was disproportionately elevated to the low 25-OH-D level $[1,3]$. The PTH value was normalized in a short term as seen in previous reports in which a similar spontaneous decline of PTH concentration within 4-10 days was described [19, 21, 22]. The decrease in PTH by ergocalciferol supplementation should have been slower in a chronic vitamin D deficient state. These facts suggest possible PTH resistance in addition to vitamin D deficiency. However, the exact etiology remains elusive and it requires further investigations.

Table 3. Risk Factors of Acquired Deficiency or Resistance to Vitamin D

Poor intake / malnutrition
Malabsorption
Diarrhea
Poor sunlight exposure
Skin pigmentation
Liver disease
Renal disease
Hypomagnesemia
Older age
Anticonvulsant-drug therapy

Recent investigation has revealed vitamin D-binding protein (DBP), also known as Gc-globulin, is an acute phase reactant which falls in the event of acute disease. Dhal, et al. [39] reported that it decreased acutely to $87 \%$ of baseline value following surgery, suggesting that acute situations potentially result in acutely low $25-\mathrm{OH}-\mathrm{D}$ even in a patient with reasonable body stores. Although $88 \%$ of $25-\mathrm{OH}-\mathrm{D}$ is bound to this protein in the serum [40], only $5 \%$ of the binding sites are normally occupied on the circulating DPB. Thus, an even higher decrement in DBP is required to significantly lower serum 25-OH-D [41]. Such reductions occur in only a few clinical conditions such was severe hepatic failure, nephrotic syndrome, and severe malnutrition [42, 43], and our cases were not compatible with these clinical conditions. 
In conclusion, vtamin D deficiency is common but frequently overlooked. This is the first report to our knowledge that followed the serial values of serum calcium and PTH in response to vitamin D treatment in the setting of acute illness. It should be assessed as a cause of hypocalcemia because it is simply treatable as illustrated here. Our cases point up the fundamental fact that severe hypocalcemia constitutes an emergency that requires immediate attention and appropriate treatment to prevent life-threatening events.

\section{ACKNOWLEDGMENT}

We are grateful to Dr. M. Larissa Aviles-Santa for her clinical advice during the care of these patients.

\section{REFERENCES}

[1] Thomas MK, Lloyd-Jones DM, Thadhani RI, et al. Hypovitaminosis D in medical inpatients. N Engl J Med 1998; 338: 777-83.

[2] Tangpricha V, Colon NA, Kaul H, et al. Prevalence of vitamin D deficiency in patients attending an outpatient cancer care clinic in Boston. Endocr Pract 2004; 10: 292-3.

[3] Gloth FM, 3rd, Gundberg CM, Hollis BW, et al. Vitamin D deficiency in homebound elderly persons. JAMA 1995; 274: 1683-6.

[4] Passeri G, Pini G, Troiano L, et al. Low vitamin D status, high bone turnover, and bone fractures in centenarians. J Clin Endocrinol Metab 2003; 88: 5109-15.

[5] Cigolini M, Iagulli MP, Miconi V, et al. Serum 25-hydroxyvitamin D3 concentrations and prevalence of cardiovascular disease among type 2 diabetic patients. Diabetes Care 2006; 29: 722-4.

[6] Gordon CM, DePeter KC, Feldman HA, et al. Prevalence of vitamin $\mathrm{D}$ deficiency among healthy adolescents. Arch Pediatr Adolesc Med 2004; 158: 531-7.

[7] Plotnikoff GA, Quigley JM. Prevalence of severe hypovitaminosis D in patients with persistent, nonspecific musculoskeletal pain. Mayo Clin Proc 2003; 78: 1463-70.

[8] Tangpricha V, Pearce EN, Chen TC, et al. Vitamin D insufficiency among free-living healthy young adults. Am J Med 2002; 112(8): 659-62.

[9] Meunier PJ. Prevention of hip fractures. Am J Med 1993; 95: 75S-8S.

[10] Chapuy MC, Arlot ME, Duboeuf F, et al. Vitamin D3 and calcium to prevent hip fractures in the elderly women. N Engl J Med 1992; 327: $1637-42$.

[11] Chapuy MC, Arlot ME, Delmas PD, et al. Effect of calcium and cholecalciferol treatment for three years on hip fractures in elderly women. BMJ 1994; 308: 1081-2.

[12] Dawson-Hughes B, Harris SS, Krall EA, et al. Effect of calcium and vitamin D supplementation on bone density in men and women 65 years of age or older. N Engl J Med 1997; 337: 670-6.

[13] Halterman JS, Smith SA. Hypocalcemia and stridor: an unusual presentation of vitamin D-deficient rickets. J Emerg Med 1998; 16: 41-3.

[14] Connor TB, Rosen BL, Blaustein MP, et al. Hypocalcemia precipitating congestive heart failure. N Engl J Med 1982; 307: 869-72.

[15] Carlstedt F, Lind L. Hypocalcemic syndromes. Crit Care Clin 2001; 17: 139-53, vii-viii.

[16] Cardenas-Rivero N, Chernow B, Stoiko MA, et al. Hypocalcemia in critically ill children. J Pediatr 1989; 114: 946-51.

[17] Carlstedt F, Lind L, Rastad J, et al. Parathyroid hormone and ionized calcium levels are related to the severity of illness and survival in critically ill patients. Eur J Clin Invest 1998; 28: 898-903.

[18] McKay C, Beastall GH, Imrie CW, et al. Circulating intact parathyroid hormone levels in acute pancreatitis. Br J Surg 1994; 81: 357-60.

[19] Burchard KW, Gann DS, Colliton J, et al. Ionized calcium, parathormone, and mortality in critically ill surgical patients. Ann Surg 1990; 212: 543-9; discussion 9-50.
[20] Carlstedt F, Lind L, Wide L, et al. Serum levels of parathyroid hormone are related to the mortality and severity of illness in patients in the emergency department. Eur J Clin Invest 1997; 27: 977-81.

[21] Hauser CJ, Kamrath RO, Sparks J, et al. Calcium homeostasis in patients with acute pancreatitis. Surgery 1983; 94: 830-5.

[22] Imrie CW, Beastall GH, Allam BF, et al. Parathyroid hormone and calcium homeostasis in acute pancreatitis. Br J Surg 1978; 65: 71720.

[23] Lind L, Carlstedt F, Rastad J, et al. Hypocalcemia and parathyroid hormone secretion in critically ill patients. Crit Care Med 2000; 28: 93-9.

[24] Muller B, Becker KL, Kranzlin M, et al. Disordered calcium homeostasis of sepsis: association with calcitonin precursors. Eur J Clin Invest 2000; 30: 823-31.

[25] Zaloga GP, Chernow B. The multifactorial basis for hypocalcemia during sepsis. Studies of the parathyroid hormone-vitamin D axis. Ann Intern Med 1987; 107: 36-41.

[26] Desai TK, Carlson RW, Geheb MA. Parathyroid-vitamin D axis in critically ill patients with unexplained hypocalcemia. Kidney Int Suppl 1987; 22: S225-8.

[27] Silverberg SJ, Bilezikian JP. Cytokines in primary hyperparathyroidism--factors that matter. J Clin Endocrinol Metab 1996; 81: 3448-9.

[28] Richardson JP. Vitamin D deficiency-The once and present epidemic. Am Fam Physician 2005; 71: 241-4.

[29] Wang R, Wu L, Karpinski E, et al. The changes in contractile status of single vascular smooth muscle cells and ventricular cells induced by bPTH-(1-34). Life Sci 1993; 52: 793-801.

[30] Baczynski R, Massry SG, Kohan R, et al. Effect of parathyroid hormone on myocardial energy metabolism in the rat. Kidney Int 1985 27: 718-25.

[31] Rostand SG, Drueke TB. Parathyroid hormone, vitamin D and cardiocascular disease in chronic renal failure. Kidney Int 1999; 57: 7401.

[32] Block G, Port FK. Calcium phosphate metabolism and cardiovascular disease in patients with chronic kidney disease. Semin Dialysis 2003; 16: 140-7.

[33] Vestergaard H, Ostergaard Kristensen L. Normocalcemia and persistent elevated serum concentration of 1-84 parathyroid hormone after operation for sporadic parathyroid adenoma: evidence of increased morbidity from cardiovascular disease. World J Surg 2002; 26: 65760.

[34] Zaloga GP. Hypocalcemia in critically ill patients. Crit Care Med 1992; 20: 251-62.

[35] Khan F, Khan AJ, Papagaroufalis C, et al. Reversible defect of neutrophil chemotaxis and random migration in primary hyperparathyroidism. J Clin Endocrinol Metab 1979; 48: 582-4.

[36] Malabanan A, Veronikis IE, Holick MF. Redefining vitamin D insufficiency. Lancet 1998; 351: 805-6.

[37] Holick MF. Vitamin D: the underappreciated D-lightful hormone that is important for skeletal and cellular health. Curr Opin Endocrinol Diabees 2002; 9: 87-98.

[38] Meyer C. Scientists probe role of vitamin D: deficiency a significant problem, experts say. JAMA 2004; 292: 1416-8.

[39] Dahl B, Schiodt FV, Gehrchen PM, et al. Gc-globulin is an acute phase reactant and an indicator of muscle injury after spinal surgery. Inflamm Res 2001; 50: 39-43.

[40] Bikle DD, Siiteri PK, Ryzen E, et al. Serum protein binding of 1,25dihydroxyvitamin D: a reevaluation by direct measurement of free metabolite levels. J Clin Endocrinol Metab 1985; 61: 969-75.

[41] Cooke NE, Haddad JG. Vitamin D binding protein. In: Feldman D, Glorieux F, Pilce JW, Eds. Vitamin D. San Diego: Academic Press; 1997; pp. 87-101.

[42] Gloth FM, 3rd, Tobin JD. Vitamin D deficiency in older people. J Am Geriatr Soc 1995; 43: 822-8.

[43] Cooke NE, Haddad JG. Vitamin D binding protein (Gc-globulin). Endocr Rev 1989; 10: 294-307. 